\section{Paranoid Ideation}

Natalie Dattilo

Department of Psychiatry, Indiana University

School of Medicine, Indianapolis, IN, USA

\section{Synonyms}

\section{Paranoia}

\section{Definition}

An exaggerated or grandiose belief, usually not of a delusional nature, that one is being harassed, persecuted, or unfairly treated. A general suspiciousness of others' motives or intent. Most often associated with paranoid personality disorder but also seen in borderline personality disorder.

\section{Cross-References}

- Borderline Personality Disorder

- Paranoid Personality Disorder

- Paranoid Psychosis

\section{References and Readings}

American Psychiatric Association. (2013). Diagnostic and statistical manual of mental disorders: DSM-5. Washington, DC: American Psychiatric Association.

Sadock, B. J., \& Sadock, V. A. (2007). Signs and symptoms in psychiatry. In Kaplan \& Sadock's synopsis of psychiatry: Behavioral sciences/clinical psychiatry (10th ed., pp. 272-283). Philadelphia: Lippincott Williams \& Wilkins. 